\title{
НАНОЧАСТИЦЫ ЗОЛОТА ДЛЯ ДИАГНОСТИКИ И ТЕРАПИИ ОНКОЛОГИЧЕСКИХ ЗАБОЛЕВАНИЙ
}

\author{
П. Б. Курапов ${ }^{1 凶}$, Е. Ю. Бахтенко² \\ ' Российский национальный исследовательский медицинский университет имени Н. И. Пирогова, Москва \\ ² Вологодский государственный университет, Вологда
}

\begin{abstract}
Химическая стабильность, низкая токсичность, относительная простота методов синтеза и модификации наночастиц (НЧ) золота способствуют их использованию в различных областях биомедицины, таких как диагностика in vitro, адресная доставка лекарств, фототермическая и фотодинамическая терапия. Высокое соотношение площади поверхности к объему этих НЧ существенно облегчает создание на их основе комплексных наноплатформ, используемых сразу в нескольких терапевтических и диагностических направлениях. Уникальные электрические и оптические свойства НЧ золота, известные как локализованный поверхностный плазмонный резонанс особенно актуальны для диагностики различных заболеваний. Рассмотрены основные методы синтеза и модификации НЧ золота, в частности методами «зеленой химии», фармакологические аспекты их применения и использования в качестве диагностических агентов. По нашему мнению, именно благодаря своим уникальным свойствам наноплатформы для адресной доставки лекарственных препаратов и тераностики, созданные на основе НЧ золота, имеют неоспоримые преимущества перед другими типами наночастиц.
\end{abstract}

Ключевые слова: наночастицы золота, нанодиагностика, нанотерапия, адресная доставка лекарственных средств, тераностика, онкология

$\varangle$ Для корреспонденции: Павел Борисович Курапов

ул. Островитянова, д. 1, г. Москва, 117997; kurapoff@mail.ru

Статья получена: 29.11.2018 Статья принята к печати: 18.12.2018

DOI: 10.24075 /vrgmu.2018.090

\section{GOLD NANOPARTICLES IN THE DIAGNOSIS AND TREATMENT OF CANCER}

Kurapov PB ${ }^{1}$, Bakhtenko EYu²

${ }_{1}^{1}$ Pirogov Russian National Research Medical University, Moscow

${ }^{2}$ Vologda State University, Vologda

Due to chemical stability, low toxicity, and relative simplicity of synthesis/modification techniques, gold nanoparticles (NP) enjoy a wide range of biomedical applications, including in vitro diagnostics, targeted drug delivery, contrast-enhanced radiation therapy, and photothermal therapy. The high ratio of the gold NP surface area to their volume facilitates design of complex nanoplatforms for various therapeutic and diagnostic purposes. Unique electrical and optical properties of gold NP known as surface plasmon resonance assist medical diagnosis. In this work we look at the basic methods for gold NP synthesis and modification, including the so-called green chemistry, talk about the pharmacological aspects of their application and highlight their potential as diagnostic agents. We believe that due to their unique properties, gold-based nanoplatforms for targeted drug delivery and theranostics have indisputable advantages over other nanoparticles.

Keywords: gold nanoparticles, nanodiagnostics, nanotherapy, targeted drug delivery, theranostics, cancer research

$\triangle$ Correspondence should be addressed: Pavel B. Kurapov

Ostrovityanova 1, Moscow, 117997; kurapoff@mail.ru

Received: 29.11.2018 Accepted: 18.12.2018

DOI: $10.24075 /$ brsmu.2018.090

Началом применения наночастиц (НЧ) золота в биомедицине можно считать работу, в которой конъюгированные с коллоидным золотом антитела использовали для прямой микроскопической визуализации поверхностных антигенов сальмонеллы [1]. В настоящее время это направление сформировалось в отдельную самостоятельную отрасль знаний, включающую в себя использование НЧ золота в биомедицинских исследованиях, диагностике, биосенсорах, фототермической и фотодинамической терапии, а также в адресной доставке лекарств и генетических материалов [2].

Интерес исследователей к НЧ золота постоянно растет, увеличивается количество научных публикаций, посвященных этой теме (рис. 1).

По строению и использованию НЧ золота можно разделить на две большие группы. Первая включает в себя конъюгаты НЧ с молекулярными структурами, обладающими самыми разнообразными функциями и свойствами. Такие структуры используют, например, для адресной доставки и контролируемого высвобождения противораковых лекарственных средств [3], локальной гипертермии опухолей [4], а также для оптической визуализации и создания сенсоров [5]. Важным при использовании НЧ золота для целей биомедицины являются хорошо разработанные способы синтеза, а также простота и надежность методов модификации их поверхности. Существующие методики позволяют легко присоединять к поверхности НЧ золота олигонуклеотиды, пептиды и полиэтиленгликоль.

Ко второй группе следует отнести полые НЧ с диэлектрическим или магнитным ядром и золотой оболочкой. Такие структуры используют для инкапсуляции лекарственных препаратов. Размеры НЧ золота могут 
меняться от 20 до 500 нм, что позволяет легко оптимизировать их биораспределение в условиях пассивной адресной доставки. Главным достоинством таких многослойных частиц является их полифункциональность, которая реализуется за счет разделения функций ядра и оболочки.

НЧ золота имеют повышенное сечение поглощения и рассеивания света, а характер их спектра поглощения зависит от размера и формы. Например, сферические НЧ $\mathrm{Au}^{0}$ диаметром 10-25 нм поглощают в области 520 нм, а золотые наностержни - в ближнем ИК-диапазоне. Эту их особенность можно использовать для диагностики и терапии in vivo.

Модифицированные НЧ золота обладают низкой иммуногенностью и высокой биосовместимостью. Такие частицы размером 10-22 нм можно использовать в качестве носителя для доставки вакцин [6]. Показано, что $\mathrm{H} \mathrm{Au}^{0}$ усиливают иммунный ответ in vivo, особенно в отношении вирусных инфекций - клещевого энцефалита, ВИЧ и гепатита B.

Благодаря уникальным электрическим и оптическим свойствам и способности образовывать прочные комплексы с биомолекулами НЧ золота активно используют при конструировании биосенсоров. Так, были сконструированы ДНК-биосенсоры на основе оксида графена, модифицированного ночастицами $\mathrm{Au}^{0}$, для обнаружения ряда биомаркеров, в том числе белка, локализованного на поверхности клеток рака молочной железы.

Известно, что концентрация человеческого С-реактивного белка плазмы крови повышается при воспалении. Этот белок используют в клинической диагностике как индикатор многих болезней, в том числе при сердечнососудистых заболеваниях $[7,8]$. Была разработана методика электрохимического определения в плазме крови специфического биомаркера повреждения ткани миокарда (тропонин I) по регистрации сигнала $\mathrm{H}^{4} \mathrm{Au}^{0}$, локализованных на поверхности электрода [9].

\section{Методы синтеза НЧ золота}

НЧ золота синтезируют с помощью двух основных методик - дисперсионной или конденсационной. Диспергирование, как правило, происходит за счет жесткого физического воздействия на металл, например, с использованием электрического тока высокого напряжения. При конденсационных методах НЧ восстановленного металла образуются из ионов соответствующих солей путем мягкого фризического (радиолиз, воздействие ультразвуком и др.) или химического воздействия [2]. Основным недостатком дисперсионных методов является образование неоднородных по величине частиц. По этой причине конденсационные способы синтеза НЧ золота в настоящее время наиболее распространены.

Конденсационный синтез $\mathrm{H4} \mathrm{Au}^{0}$ основан на получении коллоидных частиц диаметром 5-20 нм из галогенидов золота, в частности из тетрахлороаурата водорода, образующегося при растворении золота в царской водке. В качестве химических восстановителей используют цитрат или боргидрид натрия, аскорбиновую или этилендиаминтетрауксусную кислоты, а также щелочной раствор перекиси водорода. Для получения ультрадисперсных золей (диаметр частиц 2-3 нм) используют тиоцианат натрия или калия.

Скорость образования НЧ зависит от концентрации реагирующих веществ и химической природы восстановителя. При низкой скорости возникновения зародышей и достаточно высокой скорости конденсации частиц образуется относительно малое количество сравнительно крупных частиц. При малой скорости конденсации увеличивается вероятность образования большого количества частиц относительно малого размера.

Для получения НЧ золота размерами 8-120 нм, которые преимущественно и используются для медицинских целей, наиболее распространен метод цитратного восстановления тетрахлороаурата водорода, разработанный для получения НЧ золота со средним диаметром $20 \pm$ 1,5 нм [10]. Крупные НЧ золота диаметром более 80 нм можно синтезировать конденсационным методом с использованием в качестве восстановителя изоаскорбиновой кислоты в присутствии защитного коллоида гуммиарабика.

Для получения монодисперсных золей НЧ золота иногда используют метод двухфазного синтеза. На первой стадии металлсодержащие реагенты переводят из водной фазы в органическую (гексан, толуол), к которой затем добавляют растворы поверхностно-активных веществ и восстановителя. В качестве восстановителя можно использовать бутанол, а в качестве модификатора поверхности нанокластеров применяют гексадециламин, который координирует аминогруппа по поверхности металла, оставляя снаружи неполярные углеводородные радикалы. Использование двухфазных технологий позволяет получать монодисперсные золи золота [11].

Тип восстановителя влияет не только на размер, но и на форму частиц золота. Например, при использовании лимоннокислого натрия или пероксида водорода получаются сферические частицы, а при восстановлении гидроксиламином - хорошо ограненные кубические кристаллы с гранями [12].

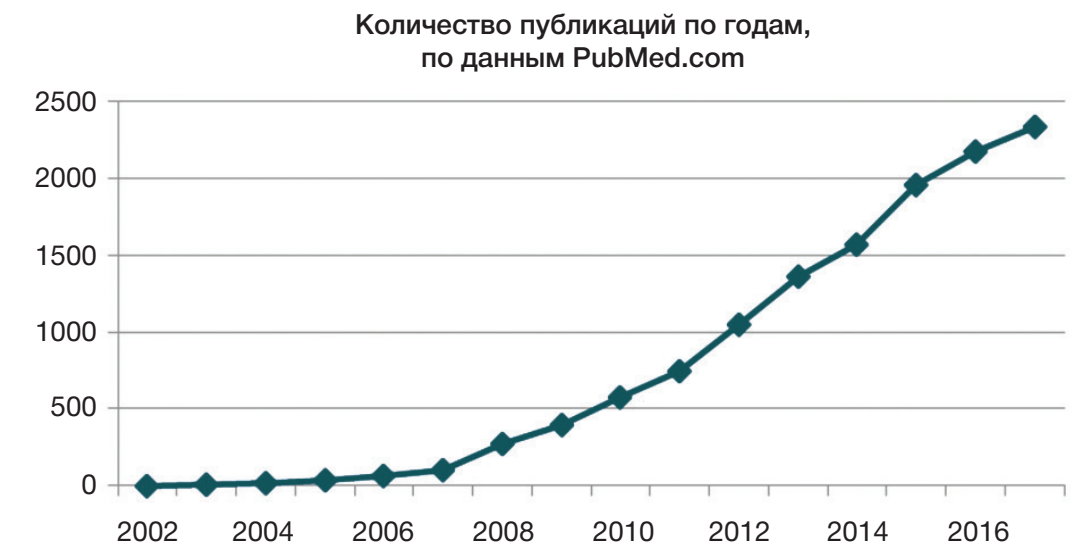

Рис. 1. Рост числа научных публикаций по биомедицинскому использованию НЧ золота в период с 2002 по 2017 г., по данным caйта PubMed.com 
Для стабилизации НЧ золота используют тиолы и дисульфиды. Высокое сродство серы к золоту служит причиной образования на поверхности НЧ монослоя тиолята золота. Кроме химических методов для восстановления галогенидов золота применяют и физические методы, основанные на использовании ультразвука, ультрафиолетового или инфракрасного (ИК) ионизирующих излучений, а также лазерного фотолиза и электрохимии. Преимущество этих методик состоит в том, что на поверхности образующихся НЧ отсутствуют примесные остатки химических реагентов.

Новым направлением в нанобиотехнологии стало использование для синтеза НЧ золота микроорганизмов, а также клеток растений, животных и человека. В его основе лежат принципы так называемой «зеленой химии» $[13,14]$. На наш взгляд, методы «зеленой химии», применяемые для синтеза НЧ золота, - уникальная возможность использования этой прогрессивной технологии. Следует заметить, что подобные подходы практически не применяются для синтеза других типов наночастиц.

Недавно был опубликован обзор данных по синтезу металлических НЧ с использованием растительных экстрактов [15]. Растения содержат определенные биологически активные соединения, такие как флавоноиды, фенолы, лимонная и аскорбиновая кислоты, полифенолы, терпены, алкалоиды и редуктазы, которые играют роль восстановителей [16]. Биотехнологический синтез НЧ имеет определенные преимущества перед химическими методами, поскольку растительные экстракты выступают в роли не только восстановителя, но и в качестве стабилизирующих и изолирующих агентов (таблица).

Растения могут синтезировать НЧ как внутриклеточно, так и внеклеточно [23]. Внутриклеточные методы синтеза НЧ включают выращивание растения на богатых металлом органических средах (клеточная, тканевая инженерия гидропоника) или почвах [24]. Внеклеточные методы синтеза НЧ основаны на использовании листового экстракта [25]. Синтезированные с помощью биотехнологических методик НЧ золота имеют различные размеры и формы: сферические, стержневые, кубические, треугольные.

Сообщается о простом, экономичном и воспроизводимом синтезе сферических и почти монодисперсных НЧ золота размером 20 нм с использованием экстракта свежих или сухих листьев манго (Mangifera indica). НЧ были получены в течение 2 мин добавления экстракта к раствору $\mathrm{HAuCl}_{4} \cdot 3 \mathrm{H}_{2} \mathrm{O}$, при этом коллоидный раствор оставался стабильным более 5 месяцев. Меньшие по размеру и равномерно распределенные частицы могут быть получены с высушенным лиственным экстрактом [26].
Размер синтезируемых методами зеленой химии НЧ золота зависит от того, какой экстракт используется в качестве восстанавливающего и стабилизирующего агента. Так, например, экстракт из листьев оливкового дерева позволяет получить НЧ Аu размером 50-100 нм, экстракт герани образует частицы размером около 12 нм, а вытяжка из листьев белой ивы - 50-80 нм [26]. Экстракты, полученные из других органов (пыльцы, семян, соцветий, коры и корней) растений, также можно использовать для успешного синтеза НЧ золота [27]. Описан метод синтеза НЧ золота с использованием хитозана в качестве восстановителя и стабилизирующего агента. Положительно заряженные частицы, содержащие хитозан, были использованы для снижения побочных эффектов противоракового препарата 5-фторурацила [28]

Сферические $\mathrm{HЧ} \mathrm{Au}^{0}$ формируются из коллоидных растворов при восстановлении $\mathrm{HAuCl}_{4}$. Ha первом этапе синтеза происходит быстрое восстановление части тетрахлороаурата водорода с образованием перенасыщенного раствора восстановленного золота. Затем восстановление резко замедляется и происходит конденсация новой фазы с образованием очень мелких зародышевых НЧ диаметром менее 2 нм. Скорость образования зародышей новой фазы зависит от степени насыщенности раствора, а также от концентрации и химической природы восстановителя. При низкой скорости возникновения зародышей и высокой скорости конденсации частиц образуется малое количество сравнительно крупных частиц. Более высокая скорость возникновения зародышей и малая степень конденсации частиц увеличивает вероятность образования большого количества НЧ малого размера.

Для целенаправленного получения несферических коллоидных НЧ золота необходимо создать искусственно анизотропные условия роста. Для этого НЧ синтезируют электрохимическим методом на жестких матрицах оксида кремния или алюминия [29]. Наностержни получают методом восстановления на мягких матрицах, представляющих собой мицелярный раствор поверхностно-активных веществ.

В последние годы активно развивается наномедицина ультрамалых НЧ размером менее 6 нм. Малые золотые наностержни (диаметр < 6 нм) обладают такими же оптическими и электронными свойствами, как и крупные наностержни, но лишены их недостатков при использовании в биомедицинских целях [30]. Нанонити золота могут быть получены после термообработки НЧ золота, адсорбированных на поверхности нанотрубок. Удалением остатков нанотрубок нагреванием могут быть изготовлены золотые трубчатые нити с внешним диаметром

Таблица. Растительные экстракты для синтеза НЧ золота

\begin{tabular}{|c|c|c|c|c|}
\hline $\begin{array}{c}\text { Традиционное название } \\
\text { растения }\end{array}$ & $\begin{array}{c}\text { Латинское название } \\
\text { растения }\end{array}$ & $\begin{array}{c}\text { Часть растения, которую использовали для } \\
\text { приготовления экстракта }\end{array}$ & Диаметр НЧ золота, нм & Литература \\
\hline Герань душистая & Pelargonium graveolens & Листья & 45 & [17] \\
\hline Вербена лимонная & Lippia citriodora & Листья & 36 & [17] \\
\hline Шалфей лекарственный & Salvia officinalis & Листья & 29 & [17] \\
\hline Гранат обыкновенный & Punica granatum & Плоды & 32 & [17] \\
\hline Змееголовник & Dracocephalum kotschyi & Листья & 11 & [18] \\
\hline Корица & Cinnamomum zeylanicum & Листья & 25 & [19] \\
\hline Помело & Citrus maxima & Плоды & $15-35$ & [20] \\
\hline Черемуха поздняя & Prunus serotina & Соцветия & $10-20$ & [21] \\
\hline Финиковая пальма & Phoenix dactylifera & Пыльца & $20-50$ & [22] \\
\hline
\end{tabular}


порядка 10 нм. Молекулу ДНК также можно использовать как матрицу при синтезе нанонитей.

Сферические золотые нанооболочки представляют собой тонкий слой золота на диэлектрическом ядре диаметром до 100 нм. Оптические свойства таких частиц могут быть настроены путем варьирования диаметра ядер и толщины оболочки. Золотые нанооболочки весьма перспективны в качестве диагностических и терапевтических инструментов в медико-биологических исследованиях. Предложенный в одной из работ способ получения нанооболочек состоит из четырех основных этапов: сначала получают сферические силикатные ядра, затем их поверхность функционализуют аминогруппами, на которых адсорбируются частицы золота [31].

Для контроля над физико-химическими характеристиками синтезируемых НЧ, определения их среднего диаметра и формы традиционно используют электронную микроскопию и спектрофоотометрию. Для определения размеров НЧ применяют также метод лазерной корреляционной спектроскопии (или метод динамического рассеяния света). Реже для характеристики частиц и конъюгатов используют дифференциальное центрифугирование, сканирующую и атомно-силовую микроскопию, угловое рентгеновское рассеяние, масс-спектроскопию, рентгеновскую дифракцию и другие методы.

\section{Методы модификации поверхности НЧ золота}

K основным способам модификации поверхности H4 $\mathrm{Au}^{0}$ относят адсорбционный и хемосорбционный. Стабилизация НЧ биомолекулами происходит при адсорбции полимера на поверхности НЧ за счет электростатических и гидрофобных взаимодействий. Сильный отрицательный заряд поверхности частиц золота обеспечивает их прочное адсорбционное взаимодействие со многими высокомолекулярными соединениями.

С целью повышения биосовместимости $\mathrm{HЧ}^{\mathrm{Au}}{ }^{0}$ или формирования на их основе специальных платформ для диагностики и терапии поверхность НЧ необходимо модифицицировать (функционализировать) покрытиями, слоями или связками. Возможность модифицировать поверхность НЧ контролируемым образом на молекулярном уровне необходима для придания им специфичности, чувствительности и биологической совместимости.

НЧ золота могут взаимодействовать с иммуноглобулинами, лектинами, ферментами, гормонами, липопротеидами и т. д. Использование НЧ золота в качестве своеобразных транспортных средств имеет многочисленные преимущества. Повышается растворимость препаратов, лекарства защищены от деструкции во время переноса к месту назначения; НЧ могут активно или пассивно накапливаться в органе-мишени, и контролируемо высвобождать переносимые лекарства. Особые магнитные и фототермические свойства НЧ золота расширяют спектр терапевтических методик, снижают эффективную дозу препарата и его токсичность.

Методы модификации поверхности НЧ Аu могут быть ковалентными и нековалентными. Преимущество нековалентных взаимодействий состоит в том, что при создании таких НЧ не требуется структурных модификаций терапевтических препаратов, а легкое высвобождение лекарственных средств служит предпосылкой для эффективной терапии. Заряженные или гидрофильные группы, аккумулированные на поверхности наноструктур, повышают их растворимость и облегчают взаимодействие с биомолекулами. Покрытие $\mathrm{H}^{4} \mathrm{Au}^{0}$ амфифильными полимерами повышает их растворимость и способствует неспецифическим взаимодействиям с биомакромолекулами, повышается совместимость наноструктур с белками и сродство к клеточной мембране. Применение полиэтиленгликоля для модификации поверхности НЧ золота значительно увеличивает эффективность клеточного поглощения в сравнении с немодифицированными НЧ, предотвращает агрегацию НЧ в среде с высокой ионной силой и поддерживает более длительную циркуляцию частиц в in vivo.

Модификация поверхности $\mathrm{HЧ}^{\mathrm{A}} \mathrm{Au}^{0}$ увеличивает продолжительность их жизни в кровеносной системе и способствует лучшему проникновению через стенки сосудов в клетки мишени. Модифицированные НЧ взаимодействуют с молекулами лекарственного средства и снижают его цитотоксичность. Наиболее распространенный метод модификации поверхности НЧ золота тиолирование. Это применение бифункциональных тиолов, дополнительная функциональная группа которых используется для конъюгации с биомолекулами. В качестве стабилизатора поверхности НЧ золота можно использовать модифицированный декстран. Подобные структуры очень привлекательны благодаря возможности обратимого изменения их свойств в зависимости от температуры или уровня $\mathrm{pH}$.

Подробно изложена молекулярная модификация золотых наноматериалов с использованием самоорганизованных монослоев или сложных молекулярных агрегатов [32]. Известно еще множество функциональных молекулярных линков, которые могут быть использованы для модисикации поверхности Н4, например арилдиазониевые соли [33, 34].

\section{Наночастицы золота для диагностики и терапии}

Впервые ауротерапия артритов была применена еще в 1929 г. Механизм ее действия основан на способности соединений золота, введенных в организм, угнетать макрофаги, тормозя тем самым развитие последующих патологических иммунных реакций.

Золотые «наностержни» активно поглощают излучение в ближнем ИК-диапазоне, для которого человеческое тело относительно прозрачно. Это делает их оптимальными для фототермальной терапии - избирательного разрушения патогенных агентов нагреванием. Например, НЧ золота применяют для уничтожения внутриклеточных паразитов Toxoplasma gondii, вызывающих токсоплазмоз. Для этого используют НЧ золота в комплексе с антителами. Антитело позволяет НЧ селективно связываться с мишенью, а затем под воздействием лазерного ИК-излучения НЧ нагреваются, что и приводит к гибели до 83\% токсоплазм.

НЧ золота начали применять в онкологии сравнительно недавно. Повышенный интерес исследователей к этим частицам связан с наличием у них уникальных оптических и электронных свойств (поверхностного плазмонного резонанса). Эти особые свойства, позволят осуществить революционный прорыв в диагностике и лечении онкологических заболеваний. Интегрирование в одну систему диагностических и терапевтических функций (терраностика) позволяет контролировать терапевтические реакции, что существенно облегчает как диагностику, так и терапию [35].

На поверхности многих раковых клеток экспрессирован специфический белок - рецептор эпидермального фактора роста (EFGR), который можно использовать 
в качестве маркера для диагностики и терапии онкологических заболеваний. Селективность действия НЧ на опухолевые ткани может быть также связана с особенностями строения и роста клеток опухоли. Раковые клетки растут достаточно быстро, и между ними и в их оболочке образуются значительные полости (эффект повышенной проницаемости и удерживания, EPR-effect), что облегчает проникновение НЧ непосредственно в клетку. Повышенная кислотность внутри опухолевой клетки также способствует адресной и своевременной выгрузке лекарств внутри пораженного органа.

После связывания НЧ с опухолевыми клетками пораженный орган облучают ИК-лазером малой мощности. ИК-излучение лазера поглощается НЧ золота, которые в ответ генерируют ультразвуковые и тепловые волны. Ультразвуковое излучение используют для диагностики (фотоакустическое наблюдение), а тепловые волны - для фототермальной терапии. Локальный нагрев вызывает адресное высвобождение лекарственных препаратов заключенных в золотую капсулу [36].

Золотые наностержни можно также использовать для фотоакустической диагностики, однако максимальный эффект в таргетной терапии рака обеспечивают звездообразные НЧ золота размером около 25 нм с 5-10 остроконечными лучами. Высокая площадь поверхности таких НЧ позволяет увеличить загрузки лекарственных средств, а их остроконечная форма способствует активному поглощению света, обеспечивая адресную выгрузку связанных терапевтических агентов.

Биосовместимые НЧ золота, модифицированные молекулами, которые способны селективно взаимодействовать с раковыми клетками, - идеальное средство для гипертертермического лечения опухолей [37].

\section{Ингибирование наночастицами золота образования метастазов путем повышения жесткости ядерных мембран раковых клеток}

По мере роста опухоли раковые клетки часто образуют метастазы и распространяются в близлежащие ткани и органы, поэтому для терапии онкологических заболеваний необходимо снизить миграцию и инвазию раковых клеток. Модификация $\mathrm{H}^{4} \mathrm{Au}^{0}$ лигандами, состоящими из L-аргинина, глицина и L-аспарагиновой кислоты (RGDпептид), и пептидами сигнала ядерной локализации (NLSпептид) позволила получить препарат для увеличения жесткости ядерных оболочек раковых клеток. Препарат стимулировал избыточную экспрессию белков ламина A/C и снижал способность раковых клеток к метастазированию. Свободный RGD-пептид часто используют в клеточной биологии и биотехнологии благодаря его свойству ингибировать межклеточные связи [38]. Эффективное ограничение образования метастазов оставляет больше времени для борьбы с онкологическим заболеванием [39].

\section{НЧ золота как платформы для молекулярной диагностики и лечения онкологических заболеваний}

В клинической практике постановка диагноза и лечение обычно разделены. Тем не менее интеграция диагностики и лечения (тераностика), сочетающая в себе весь спектр медицинских услуг (от ранней диагностики заболеваний, до терапии и последующего мониторинга лечения), может быть чрезвычайно полезной при терапии онкологических заболеваний. Тераностика - это сочетание специсической целевой терапии и целевых диагностических тестов с использованием так называемых наноплатформ.

При конструировании таких платформ $\mathrm{H}^{4} \mathrm{Au}^{0}$ по сравнению с другими носителями имеют существенные преимущества, связанные с их уникальными оптическими характеристиками, высокой эффективностью фототермической конверсии и значительным коэффициентом поглощения рентгеновских лучей. Поглощенная частицей золота энергия частично излучается в виде рассеянного света, а частично превращается в тепло. Таким образом, Н4 золота можно одновременно использовать как в аналитическом (диагностическом) варианте, так и для терапии опухолей методом оптической гипертермии. Изменение размера $\mathrm{H} 4$ позволяет варьировать аналитический и терапевтический параметры.

В ряде работ показано, что оптимальными для этих целей является НЧ золота размером около 13 нм. Они имеют высокую контрастность в компьютерной томографии и рентгенографии и могут с успехом использоваться для создания тераностических платсрорм [40-42].

\section{Фототермическая терапия}

Традиционная химиотерапия - это системное лечение, влияющее на весь организм. Химиотерапевтические препараты влияют на организм в целом и вызывают серьезные неблагоприятные побочные эффекты. HЧ $\mathrm{Au}^{0}$ прекрасно подходят для создания биосовместимых и высокоэффективных фототермических платформ, которые могут поглощать и эффеективно преобразовывать ближний ИК-свет в тепло. Такие частицы вызывают локальное повышение температуры и фототермически разрушают опухолевые клетки (оптическая гипертермия) [43].

Китайскими учеными созданы комплексные тераностические наноплатформы, которые способны одновременно выполнять диагностику опухоли и ее уничтожение. Внутри полых золотых НЧ находится оксид железа, обладающий парамагнитными свойствами, а на их поверхности закреплены антитела для определенного вида раковых клеток. В организм пациента НЧ вводят путем инъекции. Их перемещение можно отслеживать с помощью компьютерной томографии в режиме реального времени благодаря оксиду железа, который введен в состав НЧ. Локализованные в опухоли НЧ под действием ИК-излучения нагреваются, уничтожая раковые клетки (оптическая гипертермия; см. выше) [44].

На основе известного противоракового препарата доксорубицина и НЧ золота, загруженных в термочувствительные липосомы, созданы наноплатформы, позволяющие уничтожать раковые клетки как термическим воздействием, так и за счет инкапсулированного доксорубицина, который высвобождается непосредственно в опухолевые клетки под действием ИК-излучения. При этом локальная концентрация препарата увеличивается вместе с распадом липосомной мембраны [45].

В настоящее время уже два лекарственных препарата с внутривенным способом введения (Aurlmmune ${ }^{\mathrm{TM}}$ и AuroLase $^{\text {Tм}}$ ) прошли клиническую апробацию [46, 47].

Терапевтическое действие $\mathrm{H} 4 \mathrm{Au}^{0}$ основано на эффекте сужения кровеносных сосудов опухоли и остановке процесса образования новых кровеносных сосудов в пораженных органах или тканях (ангиогенеза). В норме в организме процессы ангиогенеза протекают с умеренной интенсивностью и активизируются только при регенерации поврежденных тканей, закупорке тромбов, 
ликвидации очагов воспаления, образовании рубца и других процессах восстановления, а также при росте и развитии организма. В опухолевых же тканях, особенно в тканях злокачественных опухолей, ангиогенез протекает постоянно и очень интенсивно, при этом клетки хорошо снабжаются кровью, получают больше питательных веществ и быстро растут.

Большинство существующих ингибиторов ангиогенеза являются антителами к фактору роста эндотелия сосудов (VEGF). НЧ золота блокируют функцию VEGF, не оказывая токсического воздействия на клетки, что является неоспоримым преимуществом перед существующими ингибиторами ангиогенеза, у которых есть серьезные побочные эффекты [48].

\section{Радиоактивное золото и его применение в онкологии}

Для лечения онкологических заболеваний используют коллоидные растворы радиоактивного золота. В медицине применяют $\mathrm{Au}^{0}$, обогащенное искусственным радиоактивным изотопом ${ }^{198} \mathrm{Au}$, который получают при нейтронном облучении природного изотопа Аu․ Период полураспада ${ }^{198} \mathrm{Au}$ составляет менее трех дней. Наличие $\beta$ - и $\gamma$-излучений позволяет создавать высокие тканевые дозы излучения и легко детектировать места локализации изотопа. Главной особенностью коллоидных растворов радиоактивного золота является их избирательное депонирование в клетках ретикулоэндотелиальной системы и на структурах соединительной ткани, что позволяет применять эти частицы и для диагностических, и для терапевтических целей. В радиоизотопной диагностике эффективны коллоидные растворы с концентрацией НЧ $\mathrm{Au}^{0}$ 3-6 мг/мл и размером 10-30 нм.

С лечебной целью применяют коллоидные растворы H4 $\mathrm{Au}^{0}$, как с однородной дисперсностью, так и полидисперсные. Радиоактивная концентрация вводимого препарата не должна превышать 4 мкюри/мл, что достигается разведением исходного препарата 0,25-0,5\%-ми растворами новокаина или хлорида натрия.

\section{ВЫВОДЫ}

Благодаря бурному развитию технологий химического синтеза НЧ золота в распоряжении исследователей имеется огромное разнообразие частиц по размеру, форме, структуре и оптическим свойствам. Для применения в медицине важна разработка эффективных технологий модификации НЧ золота различными молекулами, которые обеспечивают стабилизацию НЧ в условиях in vivo и адресное взаимодействие с биологическими мишенями. На сегодняшний день лучшими стабилизаторами принято считать тиолированные производные полиэтиленгликоля и иных молекул. Модифицированные полиэтиленгликолем частицы дольше циркулируют в кровотоке и менее подвержены атаке клеточных компонентов иммунной системы. Сегодня уже общепризнано, что конъюгаты НЧ золота являются отличными метками для клинической диагностики рака, болезни Альцгеймера, СПИДа, гепатита, туберкулеза, сахарного диабета и других заболеваний. Плазмонная фототермическая лазерная терапия рака с помощью НЧ золота перешла в стадию клинической апробации. Реальные клинические успехи этой технологии будут зависеть от того, как быстро удастся разработать надежные методы адресной доставки НЧ к опухолям внутри организма и усовершенствовать методы контроля процесса фототермолиза in situ. Создание диагностических и терапевтических платформ для адресной доставки лекарственных средств на основе НЧ золота, особенно с учетом использования для их синтеза «зеленых» технологий, является, на наш взгляд, наиболее перспективным направлением нанобиомедицины.

\section{Литература}

1. Faulk WP, Taylor GM. An immunocolloid method for the electron microscope. Immunochemistry. 1971; 8 (11): 1081-3.

2. Dykman L, Khlebtsov N. Gold Nanoparticles in Biomedical Applications. CRS Press, 2018; 331 p.

3. Sukhorukov GB, Rogach AL, Zebli B, Liedl T, Skirtach AG, Köhler $\mathrm{K}$ et al. Nanoengineered polymer capsules: tools for detection, controlled delivery, and site-specific manipulation. Small. 2005; 1 (2): 194-200.

4. Xia Y, Li W, Cobley CM, Chen J, Xia X, Zhang Q et al. Gold nanocages: from synthesis to theranostic applications. Acc Chem Res. 2011; 44 (10): 914-24.

5. Zharov VP, Kim JW, Curiel DT, Everts M. Self-Assembling Nanoclusters in Living Systems: Application for Integrated Photothermal Nanodiagnostics and Nanotherapy. Nanomed Nanotechnol Biology and Medicine. 2005; 1 (4): 326-45.

6. Kang S, Ahn S, Lee J, Kim JY, Choi M, Gujrati V et al. Effects of gold nanoparticle-based vaccine size on lymph node delivery and cytotoxic T-lymphocyte responses. J Control Release. 2017; (256): 56-67.

7. Fan L, Fang L, Yongtao $\mathrm{Y}, \mathrm{Yu}$ W, Weiqun $T$. Strategies on Nanodiagnostics and Nanotherapies of the Three Common Cancers. Nanomaterials. 2018; 8 (4): 202.

8. Antonio M, Nogueira J, Vitorino R, Daniel-da-Silva AL. Functionalized Gold Nanoparticles for the Detection of C-Reactive Protein. Nanomaterials. 2018; 8 (4): 200.

9. Шумков А. А., Супрун Е. В., Шумянцева В. В., Арчаков А. И. Сенсорный элемент на основе наночастиц золота для

определения кардиомаркеров. Биомедицина. 2011; (3): 46-9. 10. Turkevich J, Stevenson PC, Hiller JA. Study of the nucleation and growth processes in the synthesis of colloidal gold. Discuss Faraday Soc. 1951; (11): 55-75.

11. Hirai $\mathrm{H}$, Aizawa H. Preparation of stable dispersions of colloidal gold in hexanes by phase transfer. J Colloid Interface Sci. 1993; (161): 471-4

12. Михайлов М. Д. Химические методы получения наночастиц и наноматериалов. Санкт-Петербург, 2012; 260 с.

13. Anshup A, Venkataraman JS et al. Growth of gold nanoparticles in human cells. Langmuir. 2006; 21 (25): 11562-7.

14. Santhoshkumar J, Rajeshkumar S, Venkat KS. Phyto-assisted synthesis, characterization and applications of gold nanoparticles. Biochemistry and Biophysics Reports. 2017; (11): 46-57.

15. Макаров В. В., Лав А., Синицына О. В., Макарова С. С., Яминский И. В. и др. «Зеленые» нанотехнологии: синтез металлических наночастиц с использованием растений. Acta Naturae. 2014; 6 (1): 37-47.

16. Курапов П. Б., Бахтенко Е. Ю. Многообразие вторичных метаболитов высших растений и их лечебные свойства. М.: Изд-во РНИМУ, 2012; 200 с.

17. Elia P, Zach R, Hazan S, Kolusheva S, Porat Z, Zeiri Y. Green synthesis of gold nanoparticles using plant extracts as reducing agents. Int J Nanomedicine. 2014; 9 (1): 4007-21.

18. Dorosti N, Jamshidi F. Plant-mediated gold nanoparticles by Dracocephalum kotschyi as anticholinesterase agent: Synthesis, characterization, and evaluation of anticancer and antibacterial 
activity. Journal of Applied Biomedicine. 2016; 14 (3): 235-45.

19. Smitha SL, Philip D, Gopchandran KG Green synthesis of gold nanoparticles using Cinnamomum zeylanicum leaf broth Spectrochim Acta Part A Mol Biomol Spectrosc. 2009; 74 (3): 735-9.

20. Yu J, Xu D, Guan HN, Wang C, Huang LK, Chi DF. Facile onestep green synthesis of gold nanoparticles using Citrus maxima aqueous extracts and its catalytic activity. Mater Lett. 2016; (166): $110-2$.

21. Teimuri-Mofrad R, Hadi R, Tahmasebi B, Farhoudian S, et al. Green synthesis of gold nanoparticles using plant extract. Nanochem Res. 2017; 2 (1): 8-19.

22. Banu H, Renuka N, Faheem SM, Ismail R, Singh V et al. Gold and silver nanoparticles biomimetically synthesized using date palm pollen extract-induce apoptosis and regulate P53 and BCL2 expression in human breast adenocarcinoma cells. Biol Trace Elem Res. 2018; 18 (3): 12011-8.

23. Rai M, Yadav A. Plants as potential synthesiser of precious metal nanoparticles: progress and prospects. IET Nanobiotechnol. 2013; 7 (3): 117-24.

24. Masumeh N. Biosynthesis of gold nanoparticles using plant extracts. Bioprocess and Biosystems Engineering. 2015; 38 (1): $1-14$.

25. Ankamwar B. Biosynthesis of gold nanoparticles (Green-gold) using leaf extract of Terminalia catappa. E J Chem. 2010; 7 (4): 1334-9.

26. Philip D. Rapid green synthesis of spherical gold nanoparticles using Mangifera indica leaf. Spectrochim Acta Part A Mol Biomo Spectrosc. 2010; 77 (4): 807-10.

27. Vadlapudi V, Kaladhar DS. Review: green synthesis of silver and gold nanoparticles. Middle-East J Sci Res. 2014; 19 (6): 834-42.

28. Salem DS, Sliem MA, El-Sesy M, Shouman SA, Badr Y. Improved chemo-photothermal therapy of hepatocellular carcinoma using chitosan-coated goldnanoparticles. Journal of photochemistry and photobiology B Biology. 2018; 182 (5): 92-9.

29. Zhivkov A, van der Zande BMI., Stoylov S. Electro-optics of metal particles: electric birefringence of gold rods. Coll Surf A. 2002; 209 (2-3): 299-303.

30. Lu An, Yuanyuan W, Qiwei T, Shiping Y. Small gold nanorods: recent advances in synthesis, biological imaging, and cancer therapy. Materials. 2017; 10 (12): 1372.

31. Oldenburg SJ, Averitt RD, Westcott SL, Halas N. Nanoengineering of optical resonances. Chem Phys Lett. 1998; 288 (2): 243-7.

32. Love JC, Estroff LA, Kriebel JK, Nuzzo RG, and Whitesides GM. Self-assembled monolayers of thiolates on metals as a form of nanotechnology. Chem Rev. 2005; 105 (4): 1103-69.

33. Марченков Н. С., Марченко Н. В. Наночастицы золота и их применение для тераностики заболеваний человека. Медицинская физика. 2014; 4 (64): 64-77.

\section{References}

1. Faulk WP, Taylor GM. An immunocolloid method for the electron microscope. Immunochemistry. 1971; 8 (11): 1081-3.

2. Dykman L, Khlebtsov N. Gold Nanoparticles in Biomedical Applications. CRS Press, 2018; $331 \mathrm{p}$

3. Sukhorukov GB, Rogach AL, Zebli B, Liedl T, Skirtach AG, Köhler $\mathrm{K}$ et al. Nanoengineered polymer capsules: tools for detection, controlled delivery, and site-specific manipulation. Small. 2005; 1 (2): 194-200.

4. Xia Y, Li W, Cobley CM, Chen J, Xia X, Zhang Q et al. Gold nanocages: from synthesis to theranostic applications. Acc Chem Res. 2011; 44 (10): 914-24.

5. Zharov VP, Kim JW, Curiel DT, Everts M. Self-Assembling Nanoclusters in Living Systems: Application for Integrated Photothermal Nanodiagnostics and Nanotherapy. Nanomed Nanotechnol Biology and Medicine. 2005; 1 (4): 326-45.

6. Kang S, Ahn S, Lee J, Kim JY, Choi M, Gujrati V et al. Effects of gold nanoparticle-based vaccine size on lymph node delivery and cytotoxic T-lymphocyte responses. J Control Release. 2017; (256): 56-67.
34. Silva SM, Tavallaie R, Sandiford L, Tilley RD, Gooding J. Gold coated magnetic nanoparticles: from preparation to surface modification for analytical and biomedical applications. Chem Commun. 2016; 52 (48): 7528-40.

35. Guo J, Rahme K, He Y, Li LL, Holmes JD, O'Driscoll CM. Gold nanoparticles enlighten the future of cancer theranostics. International Journal of Nanomedicine. 2017; 12: 6131-52.

36. Дыкман Л. А., Хлебцов Н. Г. Золотые наночастицы в биологии и медицине: достижения последних лет и перспективы. Acta Naturae. 2011; 3 (2): 36-58.

37. Марченко Н. В., Марченков Н. С. Наночастицы золота от церковных витражей к наномедицине. Успехи в химии и химической технологии. 2012; 26 (6): 104-9.

38. Ali MRK, Wu Y, Ghosh D, Do BH, Chen K, Dawson MR et al. Nuclear membrane-targeted gold nanoparticles inhibit cancer cell migration and invasion. ACS Nano. 2017; 11 (4): 3716-26.

39. Fan L, Fang L, Yongtao Y, Yu W, Weiqun T. Strategies on Nanodiagnostics and Nanotherapies of the Three Common Cancers. Nanomaterials. 2018; 8 (4): 202.

40. Garcia CP, Chambrier I, Cook MJ, Haines AH, Field RA, Russell DA. Targeted photodynamic therapy of breast cancer cells using lactose-phthalocyanine functionalized gold nanoparticles. J Colloid Interface Sci. 2018; 512: 249-59.

41. Chen $Y$, Xianyu $Y$, Jiang, $X$. Surface modification of gold nanoparticles with small molecules for biochemical analysis. Acc Chem Res. 2017; 50 (2): 310-9.

42. Deng H, Zhong Y, Du M, Liu Q, Fan Z, Dai F, et al. Theranostic self-assembly structure of gold nanoparticles for nir photothermal therapy and $\mathrm{x}$-ray computed tomography imaging. Theranostics. 2014; 4 (9): 904-18.

43. Деев С. М., Лебеденко Е. Н. Супрамолекулярные агенты для тераностики. Биоорганическая химия. 2015; 41 (5): 539-52.

44. Hwang S, Nam J, Jung S, Song J, Doh H, Kim S. Gold nanoparticle-mediated photothermal therapy: current status and future perspective. Nanomedicine Lond. 2014; 9 (13): 2003-22.

45. Li Y, He D, Tu J, Wang R, Zu C, Chen Y et al. The comparative effect of wrapping solid gold nanoparticles and hollow gold nanoparticles with doxorubicin-loaded thermosensitive liposomes for cancer thermo-chemotherapy. Nanoscale. 2018; 10 (18): 8628-41.

46. Boisselier E, Astruc D. Gold nanoparticles in nanomedicine: preparations, imaging, diagnostics, therapies and toxicity. Chem Rev. 2009; 38 (6): 1759-82.

47. Дыкман Л. А., Богатырев В. А., Щеголев С. Ю., Хлебцов Н. Г. Золотые наночастицы: синтез, свойства, биомедицинское применение. М.: Наука, 2008; 319 с.

48. Sumbayev WV, Yasinska IM, Gibbs BF. Biomedical Applications of Gold Nanoparticles Recent Advances in Circuits. Communications and Signal Processing. Athens: WSEAS Press, 2013; p. 342-48.

7. Fan L, Fang L, Yongtao $Y$, Yu W, Weiqun T. Strategies on Nanodiagnostics and Nanotherapies of the Three Common Cancers. Nanomaterials. 2018; 8 (4): 202.

8. Antonio M, Nogueira J, Vitorino R, Daniel-da-Silva AL. Functionalized Gold Nanoparticles for the Detection of C-Reactive Protein. Nanomaterials. 2018; 8 (4): 200.

9. Shumkov AA, Suprun EV, Shumyanceva VV, Archakov Al. Sensornyj ehlement na osnove nanochastic zolota dlya opredeleniya kardiomarkyorov. Biomedicina. 2011; (3): 46-9.

10. Turkevich J, Stevenson PC, Hiller JA. Study of the nucleation and growth processes in the synthesis of colloidal gold. Discuss Faraday Soc. 1951; (11): 55-75.

11. Hirai $\mathrm{H}$, Aizawa H. Preparation of stable dispersions of colloidal gold in hexanes by phase transfer. J Colloid Interface Sci. 1993; (161): 471-4.

12. Mihajlov MD. Himicheskie metody polucheniya nanochastic nanomaterialov. Sankt-Peterburg, 2012; 260 s.

13. Anshup A, Venkataraman JS et al. Growth of gold nanoparticles in human cells. Langmuir. 2006; 21 (25): 11562-7. 
14. Santhoshkumar J, Rajeshkumar S, Venkat KS. Phyto-assisted synthesis, characterization and applications of gold nanoparticles. Biochemistry and Biophysics Reports. 2017; (11): 46-57.

15. Makarov W, Lav A, Sinicyna OV, Makarova SS, Yaminskij IV i dr. "Zelenye» nanotexnologii: sintez metallicheskix nanochastic s ispol'zovaniem rastenij. Acta Naturae. 2014; 6 (1): 37-47.

16. Kurapov PB, Baxtenko EYu. Mnogoobrazie vtorichnyx metabolitov vysshix rastenij i ix lechebnye svojstva. M.: Izd-vo RNIMU, 2012; $200 \mathrm{~s}$.

17. Elia P, Zach R, Hazan S, Kolusheva S, Porat Z, Zeiri Y. Green synthesis of gold nanoparticles using plant extracts as reducing agents. Int J Nanomedicine. 2014; 9 (1): 4007-21.

18. Dorosti N, Jamshidi F. Plant-mediated gold nanoparticles by Dracocephalum kotschyi as anticholinesterase agent: Synthesis, characterization, and evaluation of anticancer and antibacterial activity. Journal of Applied Biomedicine. 2016; 14 (3): 235-45.

19. Smitha SL, Philip D, Gopchandran KG Green synthesis of gold nanoparticles using Cinnamomum zeylanicum leaf broth. Spectrochim Acta Part A Mol Biomol Spectrosc. 2009; 74 (3): 735-9.

20. Yu J, Xu D, Guan HN, Wang C, Huang LK, Chi DF. Facile onestep green synthesis of gold nanoparticles using Citrus maxima aqueous extracts and its catalytic activity. Mater Lett. 2016; (166): 110-2.

21. Teimuri-Mofrad R, Hadi R, Tahmasebi B, Farhoudian S, et al. Green synthesis of gold nanoparticles using plant extract. Nanochem Res. 2017; 2 (1): 8-19.

22. Banu H, Renuka N, Faheem SM, Ismail R, Singh $V$ et al. Gold and silver nanoparticles biomimetically synthesized using date palm pollen extract-induce apoptosis and regulate P53 and BCL2 expression in human breast adenocarcinoma cells. Biol Trace Elem Res. 2018; 18 (3): 12011-8.

23. Rai M, Yadav A. Plants as potential synthesiser of precious metal nanoparticles: progress and prospects. IET Nanobiotechnol. 2013; 7 (3): 117-24

24. Masumeh N. Biosynthesis of gold nanoparticles using plant extracts. Bioprocess and Biosystems Engineering. 2015; 38 (1): 1-14.

25. Ankamwar B. Biosynthesis of gold nanoparticles (Green-gold) using leaf extract of Terminalia catappa. E J Chem. 2010; 7 (4): 1334-9.

26. Philip D. Rapid green synthesis of spherical gold nanoparticles using Mangifera indica leaf. Spectrochim Acta Part A Mol Biomol Spectrosc. 2010; 77 (4): 807-10.

27. Vadlapudi V, Kaladhar DS. Review: green synthesis of silver and gold nanoparticles. Middle-East J Sci Res. 2014; 19 (6): 834-42.

28. Salem DS, Sliem MA, El-Sesy M, Shouman SA, Badr Y. Improved chemo-photothermal therapy of hepatocellular carcinoma using chitosan-coated goldnanoparticles. Journal of photochemistry and photobiology B Biology. 2018; 182 (5): 92-9.

29. Zhivkov A, van der Zande BMI., Stoylov S. Electro-optics of metal particles: electric birefringence of gold rods. Coll Surf A. 2002; 209 (2-3): 299-303.

30. Lu An, Yuanyuan W, Qiwei T, Shiping Y. Small gold nanorods: recent advances in synthesis, biological imaging, and cancer therapy. Materials. 2017; 10 (12): 1372.

31. Oldenburg SJ, Averitt RD, Westcott SL, Halas N. Nanoengineering of optical resonances. Chem Phys Lett. 1998; 288 (2): 243-7.

32. Love JC, Estroff LA, Kriebel JK, Nuzzo RG, and Whitesides GM Self-assembled monolayers of thiolates on metals as a form of nanotechnology. Chem Rev. 2005; 105 (4): 1103-69.

33. Marchenkov NS, Marchenko NV. Nanochasticy zolota i ix primenenie dlya teranostiki zabolevanij cheloveka. Medicinskaya fizika. 2014; 4 (64): 64-77.

34. Silva SM, Tavallaie R, Sandiford L, Tilley RD, Gooding J. Gold coated magnetic nanoparticles: from preparation to surface modification for analytical and biomedical applications. Chem Commun. 2016; 52 (48): 7528-40.

35. Guo J, Rahme K, He Y, Li LL, Holmes JD, O'Driscoll CM. Gold nanoparticles enlighten the future of cancer theranostics. International Journal of Nanomedicine. 2017; 12: 6131-52.

36. Dykman LA, Xlebcov NG. Zolotye nanochasticy $\vee$ biologii i medicine: dostizheniya poslednix let i perspektivy. Acta Naturae. 2011; 3 (2): 36-58

37. Marchenko NV, Marchenkov NS. Nanochasticy zolota - ot cerkovnyx vitrazhej k nanomedicine. Uspexi v ximii i ximicheskoj texnologii. 2012; 26 (6): 104-9.

38. Ali MRK, Wu Y, Ghosh D, Do BH, Chen K, Dawson MR et al. Nuclear membrane-targeted gold nanoparticles inhibit cancer cell migration and invasion. ACS Nano. 2017; 11 (4): 3716-26.

39. Fan L, Fang L, Yongtao Y, Yu W, Weiqun T. Strategies on Nanodiagnostics and Nanotherapies of the Three Common Cancers. Nanomaterials. 2018; 8 (4): 202.

40. Garcia CP, Chambrier I, Cook MJ, Haines AH, Field RA, Russell DA. Targeted photodynamic therapy of breast cancer cells using lactose-phthalocyanine functionalized gold nanoparticles. J Colloid Interface Sci. 2018; 512: 249-59.

41. Chen $Y$, Xianyu $Y$, Jiang, $X$. Surface modification of gold nanoparticles with small molecules for biochemical analysis. Acc Chem Res. 2017; 50 (2): 310-9.

42. Deng $\mathrm{H}$, Zhong $\mathrm{Y}$, Du M, Liu Q, Fan Z, Dai F, et al. Theranostic self-assembly structure of gold nanoparticles for nir phototherma therapy and $\mathrm{x}$-ray computed tomography imaging. Theranostics. 2014; 4 (9): 904-18.

43. Deev SM, Lebedenko EN. Supramolekulyarnye agenty dlya teranostiki. Bioorganicheskaya ximiya. 2015; 41 (5): 539-52.

44. Hwang S, Nam J, Jung S, Song J, Doh H, Kim S. Gold nanoparticle-mediated photothermal therapy: current status and future perspective. Nanomedicine Lond. 2014; 9 (13): 2003-22.

45. Li Y, He D, Tu J, Wang R, Zu C, Chen Y et al. The comparative effect of wrapping solid gold nanoparticles and hollow gold nanoparticles with doxorubicin-loaded thermosensitive liposomes for cancer thermo-chemotherapy. Nanoscale. 2018; 10 (18): 8628-41.

46. Boisselier E, Astruc D. Gold nanoparticles in nanomedicine: preparations, imaging, diagnostics, therapies and toxicity. Chem Rev. 2009; 38 (6): 1759-82.

47. Dykman LA, Bogatyrev VA, Shhegolev SYu, Xlebcov NG. Zolotye nanochasticy: sintez, svojstva, biomedicinskoe primenenie. M.: Nauka, 2008; 319 c.

48. Sumbayev W, Yasinska IM, Gibbs BF. Biomedical Applications of Gold Nanoparticles Recent Advances in Circuits. Communications and Signal Processing. Athens: WSEAS Press, 2013; p. 342-48. 